\title{
Formative Evaluation of IT-based Services: A Case Study of a Meal Planning Service
}

\author{
Johan Blomkvist, Johan Åberg and Stefan Holmlid
}

\section{Linköping University Post Print}

\section{Tweet}

N.B.: When citing this work, cite the original article.

Original Publication:

Johan Blomkvist, Johan Åberg and Stefan Holmlid, Formative Evaluation of IT-based Services: A Case Study of a Meal Planning Service, 2014, Interacting with computers, (26), 6, 540-556. http://dx.doi.org/10.1093/iwc/iwt052

Copyright: Elsevier / Oxford University Press (OUP): Policy B - Oxford Open Option A http://www.oxfordjournals.org/

Postprint available at: Linköping University Electronic Press

http://urn.kb.se/resolve?urn=urn:nbn:se:liu:diva-105489 
Journal:

IWCOMP

Article id: $\quad$ Iwt052

The following queries have arisen while collating the corrections. Please check and advise us on the below queries.

\begin{tabular}{|l|l|l|}
\hline 1. & $\begin{array}{l}\text { Note that, Inthekab (2010) is cited in the text but not included in the } \\
\text { reference list. Please include in the reference list with complete details } \\
\text { or delete from the text. }\end{array}$ & \\
\hline 2. & Please clarify the answer for Query 5. & \\
\hline
\end{tabular}




\title{
Formative Evaluation of IT-based Services: A Case Study of a Meal Planning Service
}

\author{
JOHAN BLOMKVIST*, JOHAN ÅBERG AND STEFAN HOLMLID
}

Department of Computer and Information Science, Linköping University, SE-581 83 Linköping, Sweden

*Corresponding author: johan.blomkvist@liu.se

\begin{abstract}
To evaluate and develop a service supported by an IT (information technology) system the intention to use the future service should be in focus. The technology acceptance model (TAM) and the theory of planned behaviour (TPB) can both provide knowledge about users' intention to use a service, making them good models to base formative decisions on. Unlike TAM, TPB is concerned with specific information related to the service context, and provide knowledge about what makes IT useable. We used an adapted version of the TPB as the foundation for a formative service evaluation technique called F-SET. We applied the F-SET to a case where two subsequent versions of a service prototype were evaluated. The first prototype was a description of the service supported by $\mathrm{Hi}-\mathrm{Fi}$ design sketches showing what a web-based meal planning tool could look like. The second prototype consisted of both service processes and the web-based meal planning tool. To find relevant factors that influence future use of such a service, a survey of 28 informants was conducted with the first prototype. The second prototype involved five families who used the service for two weeks. The feedback provided by the families, based on the factors identified in the pre-test, influenced the future direction of the service development. Feedback from the informants was distributed between the service and the IT system, and the most common factors that influence the intention to use the service were time, price, usefulness and availability. Feedback included both positive and negative comments, as well as bugs and suggestions for improvements. We discuss potential improvements and what kind of information to expect from the different constructs of the TPB.
\end{abstract}

Keywords: 5.2.5 web services, 5.2.3.4 electronic commerce, 4.3.3.1 software prototyping, 1.1.1 HCI design and evaluation methods, 1.1.7 Empirical studies in HCI

Editorial Board Member: Kaisa Väänänen-Vainio-Mattila

Received 13 June 2013; Revised 16 August 2013; Accepted 7 September 2013

\section{INTRODUCTION}

New information technology (IT) solutions are many times accompanied by services that make the technology useful for people, i.e. they support goals, tasks, experiences or activities. IT can also affect customer experiences by improving service encounters (Inbar and Tractinsky, 2011). This makes IT a vital part of modern services. As mediators or channels for the service, IT needs to be considered as part of holistic experiences of service (van Dijk et al., 2007). Parallel development of IT and service means that also evaluations of IT should be integrated in service evaluations, '[ $t$ ] he success of an online service cannot be based solely upon the evaluation of the use of a website' (van Dijk et al., 2007, p. 3). As a result, several attempts to consolidate service evaluation models with evaluation methods in IT and information systems have been made (Jiang et al., 2002; Pitt et al., 1995; Watson et al., 1998). To support evaluations in those situations, a technique that generates feedback both on the level of service and IT is needed for designers. This paper suggests such a technique based on the theory of planned behaviour (TPB) (Ajzen, 1991) called the Formative Service Evaluation Technique (F-SET). The technique is developed to support early testing of service and IT prototypes, or as a technique used in iterative service and IT development, especially when truly novel services are being developed by designers. The motivation behind using the TPB is that the results of evaluation should relate to intentions 
of performing the behaviour of using the service. This means that rather than answering questions about what features and functions a service should have, the answers concern how a service should be designed to support the intentions to use a specific service, and specifically what factors influence those intentions. The difference is that instead of only asking whether or not a service is good, we ask about what makes it good and, more importantly, what aspects will affect users' interest in using the service in the future.

To illustrate the usage of the F-SET, it was applied at an early stage of the development process for a new service. Before the F-SET could be used, a period of concept design had taken place, where the what of the service (Holmlid and Evenson, 2007) had been explored. During this period the concept was detailed to enable a useful description of the service that was being developed. This description is important for F-SET, to allow customers or users to understand the future behaviour. The service was intended to allow users to plan their meals based on a database of food recipes and then place delivery orders for the related food items. The F-SET was first used to identify relevant factors that influence the intention to perform the behaviour of using the service. This was done using a low-fidelity prototype, consisting of a description of the service, explaining the main functions and two screen shots illustrating the suggested user interface. Then the service was tested using a second prototype. The whole process can be seen in Figure 1.

On a general level, the issue this research is investigating is: what type of knowledge can be generated using the F-SET? More specifically, we wanted to find out whether formative information could be generated with relevance to design, and since the technique is meant to evaluate both the IT system and the service simultaneously, we also wanted to know if design-relevant formative knowledge could be generated both in relation to the IT system and the service. Finally, to be able to use the F-SET properly we needed to create a deeper understanding of what information was associated with the constructs of TPB. In sum, to be constructive and useful, the technique should provide formative design knowledge about what is important for users, based on rough representations of the service, in the context of meal planning and home delivery of food.
IT systems are part of services, as mediators of service. When we make a distinction between the IT and service, the service should be thought of as all interactions not mediated by IT. We use the term IT or IT system to refer to digital artefacts such as programs and applications, and the term service to refer to activities such as interactions between stakeholders.

\section{THEORY}

This section provides an overview of issues in evaluation of IT systems and services, and illustrates why traditional humancomputer interaction (HCI) evaluation methods are not suitable for generating formative information on factors influencing intentions to use an IT-based service in its early development stages. Different models and theories of use intentions are also presented and the particular suitability of the TPB is described.

\subsection{Evaluation of systems and services}

Understanding intentions is a way of navigating the complexity of services. The context of the current study was the early stages of development of a service providing the ability to plan meals and order food, get food delivered, or have the option to pick up the food at a grocery store. A similar challenge can be found in Norros et al. (2011, p. 300): '[o]ur problem was that the design was still on the level of a concept and, yet, in order to test its potential, the test situation needed to be rather complex'. In these situations, understanding intentions and factors that influence the performance of behaviours in specific contexts are important.

The need to be more context-specific in evaluations has been pointed out in previous research. For instance, cultural differences entail cognitive differences (Clemmensen et al., 2009) that influence the ability to generate knowledge from prototypes. Goals of evaluations should also be developed in the specific cultural (Paterson et al., 2011) and situational context of the target users (Hvannberg et al., 2007).

The F-SET rests on the assumption that the usefulness of software and products depend on the value they provide

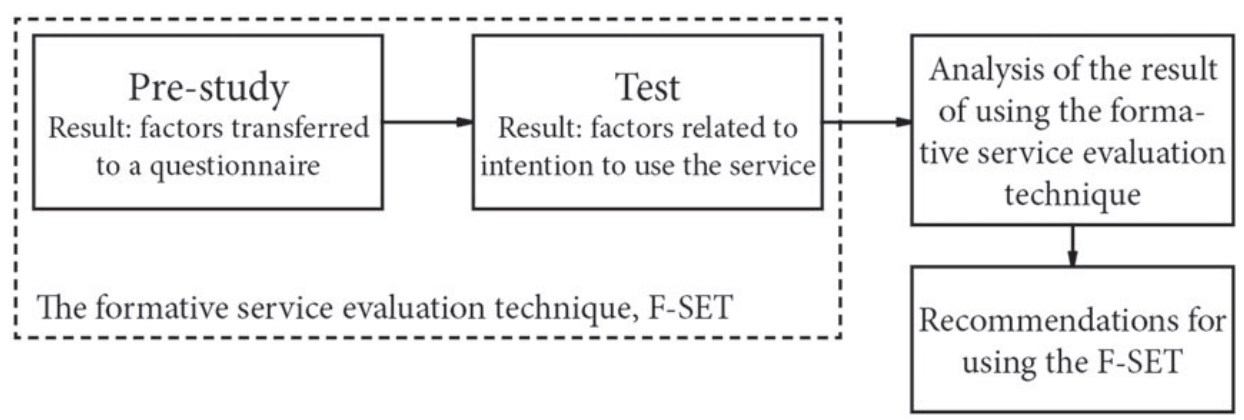

Figure 1. Description of the work process behind the paper. 
for stakeholders. This view is becoming dominant in service management and marketing fields, which have similar goals and motivations as HCI. Service-dominant logic is a perspective in service research, suggested by Vargo and Lusch (2004, 2008), contrasting the former goods-dominant logic, where the value was seen as intrinsic in products, with a view of goods as mediators in value co-creation between service providers and customers. Another similar view is expressed by interaction design researchers (Arvola, 2010; Löwgren and Stolterman, 2004), who also attempt to shift focus from intrinsic values of software and products (goods) in themselves towards a focus on value-in-use, or use qualities.

Adding services to existing offerings has long been a strategy for adding value, and distinctions between traditional manufacturers and service providers are increasingly hard to make (Vandermerwe and Rada, 1988). This is due to the many nestled and bundled product-service propositions. The shift from pure goods or mixed goods and services to a service-dominated business strategy has been labelled servitization and many advantages of servitizing have been suggested (Vandermerwe, 2000; Vandermerwe and Rada, 1988). Servitizing refers to the transition from a goods-dominant logic to a service-dominant logic. One result of this is that software and products are seen as ways to provide service for customers. For developers of software or products this means that larger considerations for use situations and value have to be made.

\subsubsection{The use of prototypes}

Wild (2010) has pointed out that there are significant similarities in the goals of HCI and service research, and that methods and approaches in HCI can benefit the area of service research. One of the proposed approaches that can benefit service research is prototyping. Prototyping has been suggested as a way to express aspects of future service experiences (Holmlid and Evenson, 2007), and been pointed out as one of the service research areas that should be prioritized (Ostrom et al., 2010).

Prototypes allow designers to get a peek into future situations before committing wholly to one of many alternative solutions and ways to implement them. Prototypes can thus be used to observe behaviours in liminal states, i.e. 'temporary "as if" circumstances, out of ordinary space-time, in a marginal position or between one context and another' (Dyrssen, 2010, p. 230) with new or altered elements that influence behaviour. As such, prototypes in design can function as learning tools (Coughlan et al., 2007) that 'may exist at any level of resolution-from very rough to highly refined-and may be used at any stage in the design process to explore, evolve, and/or communicate ideas' (Coughlan et al., 2007, p. 3).

Design is different from service development in that designers sometimes use evaluation prototypes (Floyd, 1984): representations that are made to evaluate concepts within the development process. Consequently, there are many prototyping techniques in design where rough and early representations can be used. Most evaluation models in service management are intended to test the quality of existing services (see Seth et al., 2005 for an overview).

\subsubsection{HCI evaluation methods}

An important aspect of prototypes is the ability to learn from them and extract knowledge about how successful they are. In HCI, two dominant approaches to evaluation can be identified. One focuses on the evaluation of usability, by considering aspects that either pertain to qualities of products such as reliability or portability, or by looking at qualities in use such as effectiveness, efficiency and satisfaction (Hassenzahl and Roto, 2007). The other approach focuses on user experience evaluations, where hedonic values are important (Hassenzahl, 2003).

Usability evaluation methods (UEM). Usability focusses on understanding how well systems support users' ability to perform tasks, and UEMs are used to assess those systems. UEMs can be categorized in different ways, but there are essentially three main types of methods (Hartson et al., 2003): inspection (or expert), evaluation (e.g. heuristic evaluation, Hvannberg et al., 2007; Nielsen, 1992 and cognitive walkthrough Chikhaoui and Pigot, 2010; Langdon et al., 2010; Lewis et al., 1990; Mahatody et al., 2010), model evaluation (Andre et al., 2003; Sutcliffe et al., 2000) and user evaluation (e.g. usability testing Nørgaard and Hornbaek, 2006). However, 'regardless of the method, the goal of all UEMs is essentially the same: to produce descriptions of usability problems observed or detected in the interaction design for analysis and redesign' (Hartson et al., 2003, p. 6). In this sense, UEMs are not explicitly related to discovering factors related to the intention to use a service that is being developed.

User experience evaluation. Unlike the usability paradigm, user experience extends the focus from tasks to affective aspects of interacting with products (Forlizzi and Battarbee, 2004; Hassenzahl and Tractinsky, 2006). Evaluations of user experience focus on qualities of affect and aestethics, and use tools such as the SAM (self-assessment manakin) scale (Bradley and Lang, 1994) to evaluate affect, and validated questionnaires to evaluate aesthetic qualities (Bargas-Avila and Hornbæk, 2011). Apart from having a focus on experiences of using products and artefacts (Forlizzi and Battarbee, 2004) and not on services, techniques for evaluating user experience focus on the properties of products and associated affective responses (see e.g. Hassenzahl, 2001) and not on factors that influence the intention to use a service.

\subsubsection{Service evaluation methods}

There is a long tradition within service marketing and management of evaluating service quality (Seth et al., 2005). One of the most commonly used service quality measurement instruments is SERVQUAL (Ladhari, 2009; Parasuraman et al., 1988). SERVQUAL measures the gap between expected and percieved quality on five dimensions: tangibles, reliability, responsiveness, assurance and empathy. This is a good way to 
measure the quality of existing services, and it can be used to generate knowledge that is related to users' satisfaction with the service (Jiang et al., 2002). However, the outcome of SERVQUAL is summative in nature, like most service quality measures (Seth et al., 2005), because the intention behind them is to evaluate existing and fully developed services. The outcome of SERVQUAL is a value representing service quality rather than factors that influence future use of the particular service evaluated.

\subsection{Models and theories of use intentions}

It is important in any service development process to understand why users choose to use different channels of the service proposition. Understanding salient beliefs and associated attitudes helps marketing and managing service propositions, but also the specific reasons why individuals adopt and use technological innovations are important. Much research has been conducted about attitudes and behaviours, many times looking at how to predict adoption of technology. However, understanding the steps involved in forming an opinion about a technology and understanding how attitudes are influenced by usage is a complex task. There are many temporal effects on behaviours and attitudes toward IT (Karahanna et al., 1999). Karahanna et al.'s (1999) study is particularly interesting since it highlights the problem of actually understanding what happens before an individual decides to use a product or service. This question is at the core of this paper, but we do not consider the question of what makes people choose to continue using the product or service.

\subsubsection{Information systems success}

The information systems success model (DeLone and McLean, 2003) focuses on use as a dependent variable of information system success with system quality and information quality as core components. The model includes a service quality measure. The authors "believe that "service quality," properly measured, deserves to be added to "system quality" and "information quality" as components of [information system] success' (DeLone and McLean, 2003, p. 18). Service, system and information quality are used separately to understand use and user satisfaction. The authors have suggested that use can be substituted with intention to use, since it is an attitude rather than a behaviour, and intention to use and user satisfaction have a close relationship. The argument is that first, an IT system must be used, then satisfaction judgements can be made, that in turn affect intention to use and subsequently use.

\subsubsection{Technology acceptance model (TAM)}

TAM is specifically aimed at parsimoniously explaining intention to use information systems, with perceived usefulness and perceived ease of use as central constructs (Davis et al., 1989). TAM was originally designed to predict the acceptance and usage of information systems on the job (Venkantesh et al., 2003). Perceived usefulness concerns whether subjects believe an information system would enhance job performance. Perceived ease of use however relies on a representation of an information system that allows subjects to evaluate how much effort using the system would require. TAM does not generate knowledge about what domain specific factors would influence the perceived usability and ease of use.

\subsubsection{Theory of planned behaviour}

The TPB originated in the field of social psychology and is a model for explaining behaviours. It has been shown in many studies, with many different types of behaviour, that TPB is a robust predictor of both intentions and actual behaviour, including behaviours such as IT-system adoption. With the TPB model comes a method for eliciting the salient factors affecting the forming of intentions to carry out an actual behaviour. This is the main way TPB distinguishes itself as a method from the other evaluation approaches described previously.

TPB has been found to be an accurate predictor of intentions to use IT (Mathieson, 1991) and subsequent use (Armitage and Conner, 2001; Conner et al., 2002). TPB is based on the theory of reasoned action (TRA). TRA was developed in the field of social psychology with the ultimate goal of generating knowledge about social phenomena (Ajzen and Fishbein, 1977). The core constructs of TRA are attitude towards behaviour and subjective norm. Attitude towards behaviour is how a person feels about performing the behaviour and subjective norm is a person's understanding of how significant others would react to performing the behaviour. The major critique against TRA has been that it does not account for situations where people cannot wholly exert volitional control over behaviours (Ajzen, 1991). This later led to the development of TPB which included perceived behavioural control (see Figure 2).

At the heart of the TPB is intention to perform a behaviour, which correlates strongly with performance of behaviours. Intention is influenced by peoples' attitude towards the behaviour under study, as well as subjective norm. Limiting the ability to perform behaviours is the amount of control individuals have over the situation and while the actual control is undeniably important, the perceived level of control

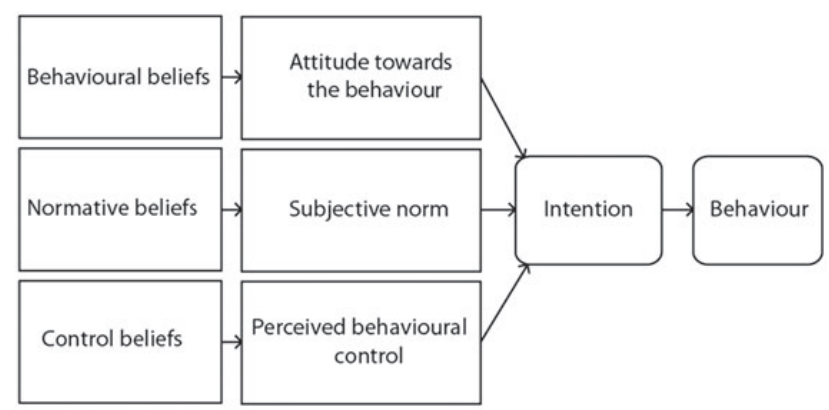

Figure 2. Model of the theory of planned behaviour. 
is more accessible in relation to intentions and behaviours of individuals. The least powerful predictor is subjective norm. Subjective norm also becomes less relevant as subjects' experience of using an IT system increases (Karahanna et al., 1999; Venkantesh et al., 2003). TPB has been successful in the sense that much research has been conducted about the theory and the tool, which has also been used in many different contexts and evaluated numerous times (see e.g. Armitage and Conner, 2001 for an overview). Since TPB is based directly on TRA, which has proved to be useful across a wide range of domains (Sheppard et al., 1988), it is suitable when new behaviours and contexts are explored. Subjective norm allows for additional insights about influences on users' behaviours.

We propose that the TPB is a helpful tool when an IT system is evaluated as part of a service due to its ability to generate insights about the specific design situation and attitudes that influence behaviours. The added value of using TPB in service prototype evaluations is that apart from revealing information about future use of services, it produces insights about attitudes about using services, people whose opinions influence usage, and peoples' perceived control over the situation and factors that influence perceived control and agency. This is done by using a predefined set of questions to first understand the relevant concepts for each situation, and then asking the resulting questions about peoples' behaviours.

\subsubsection{Comparison}

Mathieson (1991) has looked at users' intention to use an information system comparing the TPB with TAM, suggesting three main differences. First that TAM is more general, using a standard set of assumptions about IT systems and their features while TPB is concerned with situation and context specific information. Secondly, it is assumed that the inclusion of social variables in TPB can account for some variance in intention to use IT that TAM would not identify. Thirdly and lastly, for some TPB questions you might have to provide an alternative for subjects to be able to provide an answer. This comparison may be influenced by individual preferences or reference points in TPB while TAM does not require any such comparisons. Comparisons however ensure that all subjects use the same standards for their choice.

Both TAM and TPB explain intention to use IT systems well (Mathieson, 1991). On the other hand, TPB provides more specific information about an IT system; it shows several qualities of systems, it identifies barriers to using the system, and it suggests groups whose opinions might be important for system use. Also, TAM does not add knowledge about what it is that makes IT usable or easy to use (Benbasat and Barki, 2007): 'We have recommended that researchers revisit the core theory of TPB and redirect their focus toward examining different antecedents $/ . /$ to reach a more comprehensive understanding of what influences adoption and acceptance in different IT use contexts and to provide more useful recommendations for practice' (p. 216). Henderson et al. (1998) recommended that: "when considering volitional behaviour we feel that it is appropriate to consider the more encompassing TPB as the starting point for future research' (Henderson et al. 1998, p. 398). For these reasons, TPB is more suitable than TAM for generating formative knowledge for intention-to-use-focused service evaluations.

As for the information system success model, it is focussed on evaluating IT systems rather than services, as pointed out by Pitt et al. (1995). Consequently, a need to include a service quality measure has been expressed (see e.g. Kettinger and Lee, 1995; Li, 1997; Wilkin and Hewitt, 1999). Attempts to do so have mainly been done by using the SERVQUAL instrument. However, using SERVQUAL does not provide information about factors that can be used to redesign a system. It is a summative evaluation instrument, and not suitable for formative evaluation.

To summarize, TPB seems to be the best choice as a foundation for a formative service evaluation method.

\section{THE FORMATIVE SERVICE EVALUATION TECHNIQUE}

The F-SET makes use of TPB to get hold of the salient factors that influence the target users' intentions to use the planned service. The F-SET consists of two phases. The first phase is a pre-study built on TPB. The second phase is a test of a prototype of the service with the intention of gaining in-depth information of how users perceive the service with respect to the factors generated in the pre-study.

\subsection{Pre-study}

The pre-study is done by means of a questionnaire that is sent out to people representative of the intended target user group for the service to be evaluated. By means of a lo-fi representation such as scenarios and illustrative sketches, the first part of the questionnaire briefly describes the intended service, enabling the respondents to imagine themselves using the service.

The second part of the questionnaire contains questions to elicit the informants' readily accessible beliefs on behavioural outcomes, normative referents, and control factors with respect to using the described service in a certain way and for a specific time period. These questions follow Fishbein and Ajzen's (2010) proposal for eliciting salient beliefs. An illustration of this part of the questionnaire with the placeholder $X Y Z$ for the service name is shown in Table 1. In this example usage is specified as daily and the time period is specified as being for the next 3 months.

The questionnaire data are then analysed through deductive qualitative content analysis (Kondracki et al., 2002), following the procedure in Elo and Kyngäs (2008), in order to list the salient outcomes, normative referents and control factors. The resulting lists are ordered in terms of the frequency with which they were mentioned by the respondents. Note that respondents may have brought up a listed belief both as something positive and negative. 
Table 1. Questionnaire to elicit beliefs about behavioural outcome, normative referents and control factors.

Instructions: Please take a few minutes to tell us what you think about the possibility of using the $X Y Z$ service daily for the next 3 months. There are no right or wrong responses; we are merely interested in your personal opinions. In response to the questions below, please list the thoughts that come immediately to mind. Write each thought on a separate line. (Five or six lines are provided for each question.)

1. What do you see as the advantages of your using the $X Y Z$ service daily for the next 3 months?

2. What do you see as the disadvantages of your using the $X Y Z$ service daily for the next 3 months?

3. What else comes to mind when you think about using the $X Y Z$ service daily for the next 3 months.

When it comes to your using the $X Y Z$ service daily for the next 3 months, there might be individuals or groups who would think you should or should not perform this behaviour.

4. Please list the individuals or groups who would approve or think you should use the $X Y Z$ service daily for the next 3 months.

5. Please list the individuals or groups who would disapprove or think you should not use the $X Y Z$ service daily for the next 3 months.

6. Sometimes, when we are not sure what to do, we look to see what others are doing. Please list the individuals or groups who are most likely to use the $X Y Z$ service daily for the next 3 months.

7. Please list the individuals or groups who are least likely to use the $X Y Z$ service daily for the next 3 months.

8. Please list any factors or circumstances that would make it easy or enable you to use the $X Y Z$ service daily for the next 3 months.

9. Please list any factors or circumstances that would make it difficult or prevent you from using the $X Y Z$ service daily for the next 3 months.

\subsection{Test}

Based on the lists of salient beliefs elicited in the pre-study a new questionnaire is designed. This questionnaire is intended to be the basis for an interview that is carried out after a number of representative users have tested a prototype of the service. Different methods for representing the future service can be used in this phase, such as experience prototypes (Buchenau and Fulton Suri, 2000) or service walkthroughs (Blomkvist et al., 2012). The requirement is that the representation allows the user to interact with and experience the service. The questionnaire contains three parts. The first part focuses on the behavioural outcome beliefs, and lists the most frequently occurring beliefs as one semantic differential question each. For example, if the behavioural outcome belief factors time and health came up in the pre-study, the corresponding questionnaire items could be:

The XYZ service is characterized by:

Taking unnecessary time | 1||$\underline{2}|| \underline{3}|| \underline{4}|| 5 \mid$ Saving time Don't know |__

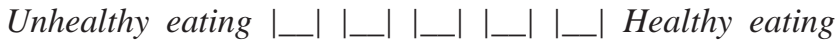
Don't know |__
The second part of the questionnaire relates to the control beliefs. For each belief factor identified, a statement is placed in the questionnaire with the informant having to decide whether that makes it more or less likely for him/her to use the service. For example, if the control belief factors technology availability and shopping list came up in the pre-study, the corresponding part of the questionnaire could be as follows.

Respond to the statements below according to whether they would make it less likely or more likely (or somewhere in between) to use the XYZ service.

That a computer is needed:

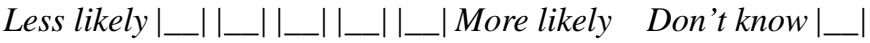 \\ That the shopping list is created automatically based on planned recipes:}

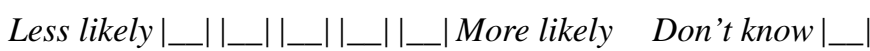

The third part of the questionnaire relates to the subjective norm beliefs, and for each belief factor identified, there will be a question as to whether that factor had a positive or negative influence, or no influence at all. For example, if the subjective norm factors children and partner came up in the pre-study, the questionnaire would be as follows:

Is there any person or groups of persons whose opinions on the XYZ service you think would affect your continued use of the XYZ service (positively or negatively)?

Yes $\left.\right|_{\ldots} \ldots$ No $\left.\right|_{\ldots} \mid$

If you have answered 'Yes', make your marks below depending on which person or group of persons you think would affect your continued usage of the XYZ service (in a negative or positive way).
Positive

I_ your children

I__ your partner

I_l others

(clarify below)

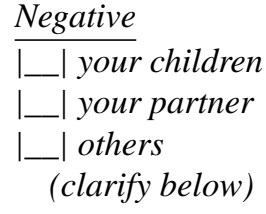

no impact $\mid$ no impact $\mid$
After an informant of the test has filled in the questionnaire it is used as a basis for an interview where the focus is on finding out the reasons behind the informant's answers. It is recommended to first go through the parts where the informant had made an answer leaning towards the negative side, and then go through answers leaning towards the positive side.

The transcription of the interview is then analysed and translated into condensed meaning units using the process described by Kvale and Brinkmann (2009). Each unit is then condensed into themes. After this procedure has been done for all the interviews, all themes are categorized and refined, and related to the three TPB factors. Finally, each theme category is given a short descriptive name. 


\section{CASE STUDY}

This section gives an example of how the F-SET was applied to the formative evaluation of a service in the domain of meal planning and online grocery shopping. The project was still in the early stages and from a business strategy point of view, it was imperative to find out more about the target users' perceptions of the service and the most important factors that could influence their willingness to use it.

\subsection{Service description}

The basic idea of the service was to help city-dwelling families with young children and two working parents with meal planning and grocery shopping. These are tasks that this particular target group often perceive as stressful, difficult and time-consuming, while still being of great importance, especially considering the health of their children.

A central part of the planned service is the web-based platform for finding food recipes, and making meal plans, as well as placing orders of the groceries contained in the planned recipes. This IT system is here referred to as MP (as in Meal Planner). Figure 3 shows a screenshot of the MP-prototype as it looked at the time of the evaluation. The part to the left of the screen is a calendar in which found food recipes could be placed using drag-and-drop. The central part of the screen shows the automatically generated shopping list, that contains all the groceries needed to cook the planned recipes, and in the right quantities. To the far right is an order button for commanding the groceries and have them packed and delivered to the user's home.
Hence, the user mainly comes in contact with the service through MP and through the grocery delivery. Behind the scenes, however, the service is more complicated. Purchase orders must be transferred to a collaborating food store, which packs the groceries and hands them over to a delivery company who brings them to the user's home and handles the payment. In other words, there are several collaborating partners and many steps where things can go wrong.

\subsection{Method}

Two prototypes of different fidelity (Rudd et al., 1996) were used to represent the future service in this study. Following the F-SET, the first step of evaluating the service was a prestudy that consisted of a web survey. The representation of the service at this early stage was a low-fidelity prototype consisting of scenarios of use, and detailed design sketches. The next step included a field test of a more high-fidelity prototype of the service, running for two and a half weeks, including a beta version of MP. Using the service prototype people could order food using MP, get food delivered to their homes or pick food up at the grocery store. This step was concluded with interviews where informants answered questions about whether the factors generated in the pre-study were addressed by the service prototype-and in what way.

\subsubsection{Phase 1-pre-study}

The pre-study survey was divided into the F-SET's prescribed two parts, and an additional third part. Owing to an on-going market survey and a request from stakeholders of the service, the third part was added.

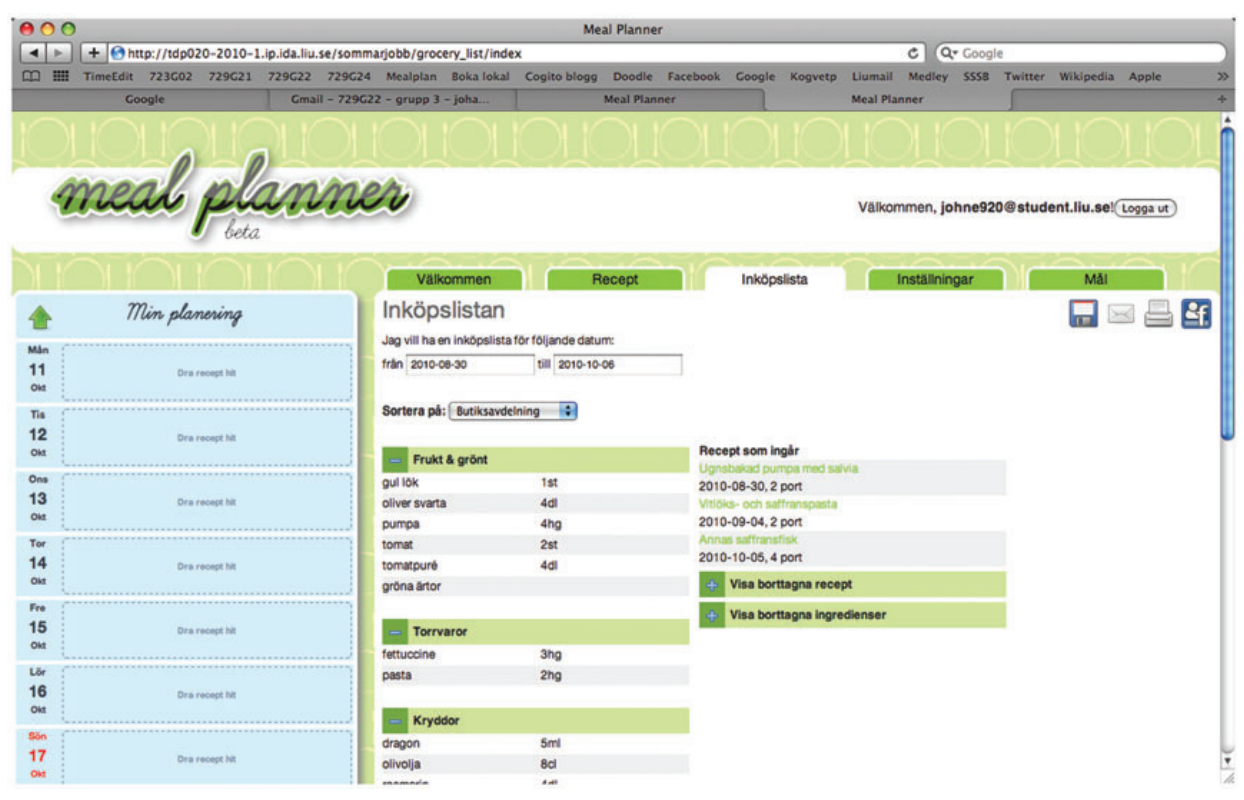

Figure 3. Screenshot from the meal planning system. 
- The first part contained a textual description of the service, complemented by two screenshots from the early MP prototype.

- The second part contained the questions to gather information concerning the TPB-factors, e.g. 'What do you see as the advantages of your using a web-based meal planning service for planning and carrying out the majority of your grocery purchases?' (see Table 1).

- The third part contained four additional questions, including a question about whether the respondents would consider using the service if it were available.

In this case we did not specify a particular time period for the behaviour. The survey was sent out through e-mail to 39 families, of which 28 answered. The respondents were chosen based on a convenience sampling strategy with the only limitation that they had to be a family with at least one child less than 10 years old.

The survey data was analysed by means of a deductive qualitative content analysis, following the detailed steps in Elo and Kyngäs (2008), in order to find the appropriate beliefs relating to the TPB factors. The frequency with which the beliefs were mentioned was also retained.

\subsubsection{Phase 2-testing the service prototype}

The second phase was directed at understanding the experience of a prototype of the service as a whole, including not only planning and ordering, but also the packing, delivery and payment process. As part of the service prototype the prototype of MP was used. At this point mainly the core functions were available-finding and planning meals by searching for recipes in a database, as well as ordering groceries through an automatically generated shopping list based on planned recipes. Some other choices were shown, but offered no functionality. This allowed the informants to form an understanding of what additional functions and options could be offered by the service. By not allowing a higher functional fidelity (McCurdy et al., 2006) focus could be turned to the core functions.

Upon placing an order it was sent to a grocery store, where the food was packed. Depending on where the users lived they either got the food delivered to their home or picked it up themselvesready and packed-from the grocery store. Grocery delivery and payment was handled by participating service stakeholders. The reason for not using an external delivery company (as intended when the service goes live) was that handling the delivery and payment was not particularly burdensome given the small number of informants and would give the participating stakeholders important first-hand experience. The analysis of this experience is however outside the scope of this paper.

As prescribed by the F-SET, the factors from the pre-study were used to create an interview guide in the shape of a questionnaire, to be used after the testing period had finished.

Five informants were used in this phase, none of whom had participated in phase 1 . Four were families meeting the requirement of having a young child at home, and one was living alone. Before the testing started, the informants were briefed individually and given an introduction to the service and the MP IT system. Given the prototype nature of MP, the informants were also informed about the limitations and that bugs were still present. The informants were asked to use the service for all their grocery shopping during the study period. They were also given information about a person to contact in case they had any questions or problems during the study.

The informants used the service for two and a half weeks, conducting the main part of their grocery shopping and meal planning using MP. An interview was then conducted with the questionnaire guiding the questions. The interviews with the four families were carried out with the person having the main responsibility of food shopping in each family. The informants were asked whether the service was working satisfactory according to the predefined factors. By answering on a 5-point scale the informants would indicate in each belief area their individual rating. Then, the questionnaire was walked through by focusing on the negative answers first and then another iteration going through the positive answers. The goal of this walkthrough was to uncover the reasoning behind the answers.

The interview material was then transcribed and translated into condensed meaning units using a predefined process (Kvale and Brinkmann, 2009). Mostly, each answer to an interview question was treated as a single condensed meaning unit, but in some cases an answer was split into several units, e.g. when the informant talked about completely different reasons for an answer to a questionnaire item. Each condensed meaning unit was then transformed into a theme. This was done separately for each interview and by different analysts. All themes from all the interviews were later categorized and further analysed, resulting in a merging of refined themes. No hierarchical themes came out of the analysis. This analysis and refinement was done as a collaborative effort with all analysts working together on a single excel sheet. After that, each remaining theme was classified into one of the three TPB belief categories (behavioural outcomes, normative referents and control factors), and given a suitable short descriptive name, used in the results presentation in the next section.

\subsection{Case results}

The results of each phase of the case will be discussed here.

\subsubsection{Phase 1 results-pre-study}

The generated factors for each belief are presented here. The numbers represent frequency of answers in terms of the number of informants that mentioned the factor. Frequency is used here to indicate what the commonly mentioned topics were-not to make any generalizations about the importance of the topic. The aim was rather to find the main factors influencing subsequent intentions to use the service. The frequency is also a result of how the phrases are categorized in the content analysis. Other 
Table 2. Behavioural beliefs.

\begin{tabular}{lc} 
Behavioural belief & Frequency \\
Time & 21 \\
Delivery & 16 \\
Usability & 13 \\
Technology availability & 10 \\
Food inspiration & 9 \\
Overview & 8 \\
Planning & 8 \\
Increased food variation & 7 \\
Price & 6 \\
Health & 6 \\
Groceries & 5 \\
Personal goals & 4 \\
\hline
\end{tabular}

ways to extract factors can be imagined and explored-see the section on Future research. Some interesting results will be highlighted in their respective belief category (Table 2-4)

Time is the factor mentioned by most informants. Saving time is considered a positive effect of using the service by many, however, some others thought that it would take more time to plan and place the orders. In terms of delivery it was considered comfortable that the groceries would be packed already and as a family you could save time and transport. The service could also decrease the amount of impulse shopping. On the negative side it would be more difficult to control the quality of the groceries and some felt that you would miss out on the experience of shopping. Some examples of how bad interface design can ruin the service and some suggestions for functionality were suggested. One observed problem is that some people do not want to use technology, but others see the usefulness of being able to order food from anywhere.

It was believed that the service could lead to more inspiration and variation in food intake, and some expressed the opinion that the IT system could provide an overview over ingredients and shopping lists, over groceries, recipes and planning. Planning in itself was experienced by some as negative by limiting spontaneity. It was expected that using the service would lead to greater variation and healthier eating but also to a more expensive food situation. Some were worried that they would no longer be able to control the amount of groceries or the brand, and that the service could potentially limit the amount of available brands. Personal goals could potentially be achieved using the service, and customisability was seen as a positive thing.

The people closest to the informants were frequently mentioned but opinions about whether they would be positive or negative in their attitude towards the behaviour varied. The informants also thought that the owners of the company behind the service should be positive to using the service. Local shop owners might be displeased however since people might not use their store as much. Variation is not something that the informants necessarily feel are prioritized by their children. In society as a whole people who care about the environment or
Table 3. Subjective norm beliefs.

\begin{tabular}{lc} 
Norm belief & Frequency \\
Partner & 7 \\
Company/store & 5 \\
Children & 4 \\
Society & 4 \\
Friends & 2 \\
Allergists & 1 \\
\hline
\end{tabular}

Table 4. Control beliefs.

\begin{tabular}{lc} 
Control belief & Frequency \\
Price & 14 \\
Technology availability & 14 \\
Usability & 14 \\
Shopping list & 9 \\
Recipes & 8 \\
Allergies & 7 \\
Delivery/packing & 6 \\
Time & 6 \\
Suggestions & 4 \\
Preferences & 3 \\
Recipe categorizing & 3 \\
Connection recipe/shopping list & 3 \\
\hline
\end{tabular}

about the person using the service could have positive feelings about the service, but it could also be the other way around and e.g. older people might not approve of the service, one informant said. Friends might also have mixed opinions about the service. Allergists would rather be positive about the service.

Also here the price will be important for the use of the service. An expensive service would prevent them from using it, while a cheaper service would positively affect some informants. From a technology point of view it was considered important that the service could be accessed from different products, for instance many would like to have an application for their smartphone. Availability would have a positive effect on their use. Poor access to technology was a limiting factor for some respondents. If the interface would be too complex that would also hinder some from using the service. Also, if the database would miss some groceries that would significantly decrease the experience of the service. The shopping list should be possible to adjust, the size of packages should be customizable, it should be possible to choose brand, and the IT system should consider what has already been bought before.

The recipes in the database would also influence use. Recipes should be simple and appealing, and there should be a significant number of different recipes to accommodate different needs such as allergies and other preferences. Many also felt that the food should be delivered to the home address. The service should not be time-consuming and lack of time could be a motivating factor for using the service. The IT system could 
also suggest menus for whole weeks and suggest recipes to make the service attractive. Categories of recipes could also improve the service, with categories like 'quick and healthy', 'parties' and 'simple food for many'. Informants also mentioned that the recipes should be coupled with the shopping list so that they would not have to do that manually.

\subsubsection{Phase 2 results-test}

In this section, we present how well the factors from the prestudy were addressed by the service prototype. The mentioned factors in test two are summarized in Table 5.

Behaviour Behavioural factors that were not mentioned during the interview were technology availability and personal goals.

Time. During the interviews based on the questionnaire, most positive comments about behaviour by the informants concerned saving time by not having to go to the grocery store to shop. It was considered negative that things did not work, which made it take a lot of time. Someone also said that the planning in itself was too time-consuming, because looking through all the recipes took too much time before making a decision. Not having a list with type and brand of groceries also made it timeconsuming because it was complicated.

Delivery. Positive answers about delivery concerned less impulse shopping, which was positive, and that the delivery in itself was good. The negative ones were about missing the experience of going to the store.

Usability. Error messages were experienced by some to increase uncertainty. Some were not sure whether they would get the groceries they had ordered or not. Except for that a number of bugs were reported.

Food inspiration. Some informants said that they had been inspired in their cooking by using MP. Some others said that the

Table 5. Behavioural and norm beliefs and control factors in phase 2 .

\begin{tabular}{lll} 
Behavioural beliefs & Norm beliefs & Control factors \\
Time & Partner & Price \\
Delivery & Company/store & Technology availability \\
Usability & Children & Usability \\
Food inspiration & Society & Shopping list \\
Overview & Friends & Recipes \\
Planning & Allergists & Allergies \\
Increased food & & Delivery/packing \\
$\quad$ variation & & \\
Health & & Time \\
Groceries & & Suggestions \\
Not getting discounts & & Preferences \\
Other & & Recipe categorizing \\
& & Connection \\
& & recipe/shopping list \\
& & Offers \\
& & Service trustworthiness \\
\hline
\end{tabular}

recipes were not appealing or that they did not experience any difference in inspiration from their usual situation.

Overview. Good overview of recipes and menu were comments that came up.

Planning. The impression of planning varied among the informants. Some were unused with planning and some felt that planning made it more difficult to be spontaneous. Many informants also considered it positive that they had to plan by using MP.

Increased food variation. Some said that they ate as varied diet as usual when using MP. One person also felt that food intake had been more varied.

Health. The participants felt that they had not eaten more or less healthy after using MP.

Groceries. Some informants made remarks about not being able to touch the fruit in the store, which led to unwillingness to buy fruit using the service. It was also difficult for some to remember which brand of grocery to order.

Not getting discounts. One informant had an opinion about missing out on discounts. The informant had searched for discounts on her own to see which ones were offered by the particular store used in this study.

Other. Some said that it would be good for the environment if more people used the service and if the delivery firm could deliver to more people at the same time.

Subjective norms. Except for the beliefs in the table there were informants who said that they were not affected by other people or groups at all. Some said that their view of the service would not change now that they had their own opinion about it and that children affect planning but not use of the service.

Partner. Some said that it would matter if the partner felt that the service was working. The partner can have both positive and negative effects.

Company/store. Those who had an opinion about the store said that marketing of the service would influence them. The supply from the store they would shop from can also be important and affect use of the service. Also the way the company behind the service would approach customers and market the service would influence them.

Children. According to the informants it was also common that children would influence them. If children for instance want to go to a store they might end up doing so.

Society. People who care about the environment were the only suggested group here. Delivering the groceries to places where a lot of people work could for instance make people who are worried about the environment more positive towards the service.

Friends. Friends influence the informants. For instance, friends who use similar services influence their own opinions and choices

Allergists. If allergists feel that they can trust the service provider that will influence their judgement. Stores should take allergies seriously because you need to be able to trust that you can eat the food. 
Control factors. The discussed control factors were the same as in the pre-study, but with the addition of two factors that emerged from users during the interviews: offers and service trustworthiness.

Price. The price was a major concern for the informants since they thought the service could get very expensive. They were worried about getting the most expensive groceries without having anything to say about it.

Technology availability. Generally they saw no barriers with using a computer and they suggested that a smartphone application would be good and that they could imagine paying for it.

Usability. From a usability point of view it was made clear that providing good solutions for the following issues were important; adjusting the number of people in recipes, printing and editing the quantity of ingredients in the shopping list.

Shopping list. Informants wanted a clear connection between the shopping list (containing ingredients) and the grocery items that the ingredients will be translated to in the store. They wanted to make their own choice of brand, etc. Also, price information was missing.

Recipes. The amount and quality of the recipes was seen as an important factor for the willingness to use the service. Some informants wanted the possibility to add their own recipes as well. On the positive side, there were some that thought the range of recipes was good, and that they were not too advanced. Furthermore, the overview of the recipes was good, and it was found to be exciting to look for recipes and make shopping lists.

Allergies. There were informants who thought it was difficult to adapt groceries according to allergies, since one for example could not specify that you wanted pasta not containing eggs.

Delivery/packing. Some of the negative opinions connected to this factor concerned the ability to feel certain groceries and see the quality. Others simply appreciated not having to go to the store. Some informants mentioned that the home delivery was good and would make it more likely to use the service. Having the possibility to choose between picking up the packed groceries in the store and having them delivered was expressed as a suggestion. There were also some negative comments about experiencing errors in the delivery in terms of missing grocery items, and that the wrong type of groceries (too expensive or not ecological) had been chosen by the food store personnel.

Time. Only one informant had an opinion related to time (in the context of control factors). The informant was not the type of person who plans, and did not like the planning in MP, which took unnecessary time.

Suggestions. One informant wanted recipes in search results to be ranked according to individual preferences.

Preferences. Similar comments to the comments on 'suggestions' above.

Recipe categorizing. It came up that some categories were missing (e.g. for outdoor cooking), but in general the categories were seen as helpful. One informant thought that the categories had no impact on the willingness to use the service.
Connection between recipes/shopping list. With respect to this connection there were only positive opinions. One informant thought it was the best part of the service.

Offers. The informants who brought this up lacked campaign offers, and several meant that discounts should be on display in MP.

Service trustworthiness. One informant lacked an order confirmation from the actual food store (not just from MP).

\section{ANALYSIS}

An analysis looking at the result of using the F-SET was conducted after the method had been used in the case. The analysis looked at both the result of phase 1 (pre-study) and phase 2 (test) and started by adding each opinion, expressed by one or more informants, to a table. The analysis template and some excerpts from the data can be seen in Table 6. Some of the collected opinions were pure suggestions, these could not be categorized as positive or negative and were given the label 'neutral'. The constructs (behaviour, control and reference groups) and factors related to each opinion were also added. The analysis then looked at each opinion to see whether it concerned the IT system or the service, and if the informants had expressed a positive or negative view. Since the F-SET should be used in formative stages the analysis also involved the generation of ideas for IT system and service redesign, as well as ideas about what stakeholder would be involved in the solution or redesign.

The actual comments made by the informants were also included in the data sheet. The comments associated with the numbers in Table 6 were:

- \#3 It could sometimes take too much time

- \#67 Suggestions for weekly menus increase the likelihood of future use

- \#82 Children would be negative towards the service

- \#16 Plan anywhere and at any time

- \#65 Less likely to use if it takes too much time

- \#92 The planning was too time-consuming

- \#160 The current categories are understandable

- \#102 Good overview of recipes and menu

- \#151 Did not like planning because it takes time

The material was analysed by three researchers, two senior and one junior. Choices of how to categorize the opinions were arrived at through consensus. The analysis also looked at the opinions by themselves, and the associated factors and constructs to discuss how they can be used. The analysis result is divided into distribution of comments and general findings.

\subsection{Analysis results}

It was important that the method could be used to gather information both about the IT system and the service, and that opinions were expressed both about the positive and negative 


\begin{tabular}{|c|c|c|c|c|c|c|c|c|}
\hline \# & $\begin{array}{l}\text { Pre/ } \\
\text { Test }\end{array}$ & Construct & Factor & $\begin{array}{l}\text { IT/ } \\
\text { service }\end{array}$ & $\begin{array}{l}\text { Positive/ } \\
\text { negative }\end{array}$ & $\begin{array}{l}\text { System } \\
\text { redesign }\end{array}$ & $\begin{array}{l}\text { Service } \\
\text { redesign }\end{array}$ & $\begin{array}{c}\text { Solution } \\
\text { owner }\end{array}$ \\
\hline 3 & Pre & Behaviour & Time & Service & - & & & \\
\hline 67 & Pre & Control & Suggestion & IT & + & & & \\
\hline 82 & Pre & $\begin{array}{c}\text { Reference } \\
\text { groups }\end{array}$ & Children & & - & & & \\
\hline 16 & Pre & Behaviour & $\begin{array}{l}\text { Technology } \\
\text { availability }\end{array}$ & IT & + & & & \\
\hline 65 & Pre & Control & Time & Service & - & & & \\
\hline 92 & Test & Behaviour & Time & Service & - & $\begin{array}{l}\text { Weekly menus, } \\
\text { customizations, save } \\
\text { previous orders, save } \\
\text { previous planning in } \\
\text { the system }\end{array}$ & & PES \\
\hline 160 & Test & Control & Time & Service & + & & & \\
\hline 102 & Test & Behaviour & Overview & IT & + & & & \\
\hline 151 & Test & Control & $\begin{array}{l}\text { Shopping } \\
\text { List }\end{array}$ & IT & - & $\begin{array}{l}\text { Provide suggestions in } \\
\text { the system }\end{array}$ & $\begin{array}{l}\text { Alternatives where the } \\
\text { food and recipes are } \\
\text { automatically } \\
\text { decided }\end{array}$ & $\begin{array}{l}\text { PES, delivery } \\
\text { firm }\end{array}$ \\
\hline
\end{tabular}

Table 6. Excerpt from the data analysis.

Table 7. The results of the analysis summarized.

\begin{tabular}{lccc} 
& Pre-study & Test & Total \\
IT & 42 & 38 & 80 \\
Service & 30 & 37 & 67 \\
Positive & 43 & 24 & 67 \\
Negative & 37 & 36 & 73 \\
Behaviour & 36 & 23 & 59 \\
Control & 39 & 51 & 90 \\
Reference group & 14 & 11 & 25 \\
\hline
\end{tabular}

aspects of them. In all, there were 80 opinions related to the IT system and 67 opinions related to the service. These were quite evenly distributed over the pre-study/test. There were also 67 positive and 73 negative opinions about either the IT system or the service (see Table 7). Also from this perspective the distribution between pre-study and test were quite even. In all six bugs were reported in relation to the IT system and one failure of the service delivery (a user received other groceries than the expected). For the bugs we did not generate any suggestions for solutions, but for all the negative comments after the test we suggested solutions.

In all, redesigns/improvements or suggestions for additional functions and services were generated for the 36 negative/test opinions, almost always for both the IT system and the service, including a remark about who would be affected by the solution or redesign. The number of negative comments about each factor from the pre-study provides an indication of how prioritized the solution/redesign is. We found solutions that would include MP, a grocery store, and the delivery firm. These actors would all have to be involved in the redesign of some of the suggested solutions.

\subsection{General findings}

The pre-study results concerning behaviour indicated which factors would influence the intention to use the service. The complete list of factors can be seen in Section 4.3.1. Phase 1 results-pre-study. Opinions in the pre-study were based on the first prototype, and reflected both positive and negative assessments. Negative control judgements were important to look further at, since critical control factors can prevent users from being able to use the service.

A categorization of the reference group comments based on the pre-study could be made. All comments were negative, i.e. all the mentioned groups could influence intention to use the service negatively.

When looking for potential ways to solve negative comments it was sometimes possible to look at suggestions made in other contexts. The comment by \#67 above is a solution to the problem introduced by \#92: that planning was too time-consuming. That can be solved by having ready-made meals provided by the service.

\section{DISCUSSION}

The F-SET suggested implications both for how to design, and how to market the service. Using the F-SET also indicated how interested the target group was in the service, in addition to providing detailed, hands-on information about the service and 
the system. In a similar study, Henderson et al. (1998) found that peer-group norms and enjoyment of using a grocery shopping system were most important for intention to use. While the general TPB questions concern the likelihood of the informants to perform a behaviour, it is also interesting to see how this method reveals information that is critical to usage on several different levels - from functionality of the IT system and its buttons to conceptual features like whether to provide home delivery or not.

One important issue for the technique to be useful was whether it could generate feedback about both the service and the system. We found that the F-SET generated comments about the two (80 IT system, 67 service), and that comments were made about both behavioural and control beliefs. It is unclear exactly what aspect of the F-SET that motivated feedback about both IT and Service, but presumably people will not make that kind of distinction when confronted with a description of the service. Instead, guided by the TPB questions, they will comment on any aspect based on whether it will influence their intention to use the service. Of course also other context and situation-specific variations in the use of the F-SET will influence the kinds of feedback that is generated. The outcome of the F-SET are assumed to be related to the intention to use the service, as previous research has shown that TPB is a powerful predictor of behaviours in various contexts (Armitage and Conner, 2001; Sheppard et al., 1988) and intentions to use IT (Mathieson, 1991). Even though distinctions between service and system are not always easy to make, this result increases our confidence that the F-SET can be useful for formative evaluations of services.

The pre-study generated factors that influenced the intention to use the service while the next step, the test, made the information more specific and substantial. So, while the first step indicated more about the service concept and the basic premise of the service, the second step produced more information about the usefulness and specific functions of the IT system and service delivery, as expected by higher fidelity representations (McCurdy et al., 2006). Underlying the F-SET is the assumption that behavioural beliefs are important for the continued use of the service. If the outcome of a behaviour is perceived as favourable, it will motivate further use of the service. Hence, the more realistic the test is, the better predictor of future adoption of the service.

\subsection{The identified factors}

The factors are many times overlapping and the same opinions expressed by the informants could sometimes be attributed to more than one factor. Some factors were also closely related, such as availability and usefulness of technology.

From the material collected it is difficult to differentiate which factors are the most important for the future use of the service, but theoretically, every factor will have some impact. In this study we looked at how many comments were made in regard to the identified factors. In the pre-study, many informants talked about time and delivery, which were also factors that were discussed extensively in the interviews. In relation to the service, most informants felt that these were areas where the service could contribute in a positive way. Time is also a recurring factor in the control beliefs category, as well as system usefulness, which will also be a deciding factor when users make their choice.

The method generated many useful insights about what MP should improve to increase the chance of a successful service. It is important to bear in mind that the constructs (behaviour, subjective norm and control) yield qualitatively different data. The beliefs about future behaviour indicate how to achieve a service that is appealing to the identified target group-what to develop further and what to avoid. The behaviour in the test shows in much more detail how those recommendations can be followed. For example,

- visualizing variation, healthiness,

- providing social functions and

- automatically suggesting menus and individual suggestions

would improve the compliance of the IT system with suggestions. In addition,

- adding the option of picking up food at the grocery store,

- sending out inspirational brochures and

- having the option to buy additional food during delivery

would improve the compliance of the service with suggestions. A similar list could easily also be made for control factors. Beliefs about control factors indicated what might prevent future use while the test made these factors more elaborate-or at least increased or decreased confidence concerning certain conceptions about barriers to use.

IT system suggestions included,

- allow changes to existing shopping lists,

- do not delete old recipes,

- use breadcrumbs ${ }^{1}$, and

- make choices of specific grocery brands available.

Service suggestions,

- add social service elements,

- sharing recipes with friends,

- provide less expensive or ecological alternatives, and

- provide expert, theme, campaign, or season ratings.

The subjective norm beliefs revealed stakeholders that influenced the willingness of informants (and presumptive users) to use the service. During the test, some more information was revealed about what kind of influence each stakeholder brings. Subjective norm revealed groups of people with certain

\footnotetext{
${ }^{1}$ Breadcrumbs aid users in navigating interfaces by showing the current location.
} 
attributes, rather than actual people. This can be both good and bad. Asking for actual people might be useful if you want to contact them directly, but groups of people such as 'affluent people' or 'inexperienced Internet users' also indicated which groups should be considered, and possibly involved, during service development. But this is not what was intended with $\mathrm{TPB}$, the groups of people may or may not influence decisions, and what the theory says is that individuals that have an impact on the decision should be identified so that prediction of the behaviour can be more accurate.

The F-SET, as used in this study, did not identify individuals that are important for intention to use. Furthermore, it did not provide a value attached to each factor that indicates its relative importance and it will not provide a value indicating the overall service quality. This means that if the generated data are considered as requirements, some additional ranking or sorting of the factors will have to be made. The impact of making changes to specific factors can only be understood if the F-SET is used in an iterative service development process, or as part of e.g. a User Centered Design (Mayhew, 1999) or Scenario Based Design (Carroll, 1999) process. The factors can then be used to direct the design process, much like design goals or requirements. As is now, it is up to the judgement of designers using the technique to decide how and what to prioritize. The most often mentioned factors are not necessarily the most important for the use of the service.

The F-SET generated usability type feedback (Hassenzahl and Roto, 2007), but not as detailed as in most UEMs (Hartson et al., 2003) related to how to implement the service. Also, a few comments related to user experience values (Hassenzahl, 2003) could be found, relating to the conceptual level and what to design. The important distinction is not whether a factor relates to hedonic or usability values, but whether it is relevant for the intention to use the service. The types of feedback will be decided by the specific service that is being developed, since that feedback concerns the intention to use that specific service in the future. The knowledge will thus be different for different services. Some have a strong emphasis on the experience, and for other services e.g. security, reliability, or efficiency, will be more important. We assume, that in a service where the hedonic qualities are more important for intention to use, such factors will be more commonly mentioned when using the F-SET, and the opposite will occur if usability ('ergonomic' in Hassenzahl, 2001) qualities are more important.

\subsection{Outcomes of the evaluation}

Several changes to the service were made based on the evaluation results, which illustrate the constructive nature of the F-SET. Examples of the ones that were deemed to be of highest priority include a decision to integrate food articles connected to ingredients. This way, the customer can choose the brand and type of food item to be ordered for each ingredient. Price information for all available food items were also added, allowing the customer to know the exact price of a placed order. To further facilitate order placement, a database with photographs of food items were also included, facilitating visual recognition of food items usually bought. Changes to the food packing routines were also made. When in doubt about an ordered food item or when an item is no longer in stock, the packer is now instructed to call the customer and discuss how to handle the situation.

\subsection{Future research}

It is possible to use the F-SET in an iterative process where each step builds upon the previous, accompanied by more and more refined versions of the service and the supporting IT system. Since the F-SET produces knowledge about both IT-system and service, it can potentially be incorporated in a number of different development approaches. An interesting future research project could include the exploration of how the F-SET fits with existing IT development processes. Both UEMs and experience evaluation methods feed into existing development processes (e.g. Carroll, 1999; Mayhew, 1999), and it should be possible to fit the F-SET into those processes. In what ways could F-SET work as a complement to other iterative evaluation techniques or to elicit usability requirements? Also, how can the various types of data that result from using the F-SET be incorporated in a User Centered Design process?

In Section 5.1, we have shown examples of data generated by the F-SET and how it can be translated into design suggestions. However, the F-SET does not currently prescribe a preferred way to translate this data into well-formed requirements. In development projects there are different roles (e.g. IT developers, project managers, marketing and service managers) that are affected by the feedback generated by using the F-SET. How may existing techniques for requirement elicitation cater to the different needs of these different roles?

Prototyping in the design sense is not a widespread practice in service development, though it has been pointed out as an area where more research should be conducted (Ostrom et al., 2010). Since the F-SET generates knowledge not only on the system level, but also on the service level it would be interesting to better understand how F-SET can be used to feed into the different existing service development processes (see e.g. Edvardsson et al., 2000; Inthekab, 2010). How would service developers make sense of and use data from the F-SET?

It is possible that the F-SET could use any of the extended or modified versions of TPB to improve the technique. Alternative suggestions include diffusion of technology, flow theory, and social network theory which have all been used together with TAM and TPB in various ways (Venkantesh et al., 2003). Self-efficacy has been mentioned as a concept related to perceived control (Ajzen, 1991), which led to a more explicit incorporation of the theory in the TPB framework (Pavlou and Fygenson, 2006), dividing control beliefs into self-efficacy beliefs and controllability beliefs. Also part of perceived 
behavioural control is previous behaviour, which could be incorporated more explicitly in the model. Other extensions have been made, see Perugini and Bagozzi (2001), which suggested the model of goal-directed behaviour, building on the assumption that desires are the proximal causes of intentions. Could the benefits of using any of these alternatives motivate adding them to the F-SET? There is a trade-off between the quality of output and the complexity of the evaluation instrument (Pavlou and Fygenson, 2006; Perugini and Bagozzi, 2001).

\section{CONCLUSIONS}

The generated feedback was analysed and categorized into factors that influence the intention to use the service. The factors that were mentioned most often were time, price, usefulness, and availability. The feedback from the informants were distributed evenly between the service and the IT system, and across behavioural and control beliefs, thus adding confidence that the F-SET can be used to evaluate IT systems in parallel with services.

The different constructs will generate different types of knowledge about how to redesign a service based on the FSET. While the pre-study reveals what the significant factors are for each construct, the following test provides additional insights about what is that influence intention to use a service. Subsequently, it is possible to transform those insights into design goals. The behavioural beliefs should then be considered as indicators about what a successful service and IT system should be and what they should offer. Control factors identify issues that might prevent future use while subjective norm factors consist of stakeholder groups in this case, and understandings of their attitudes towards the service.

Redesign of both the service and the IT system could be supported by positive and negative comments, as well as some straightforward suggestions for features and functions. A large number of suggestions were the result of looking at each comment individually. These suggestions can be prioritized based on the most often mentioned factors. In conclusion, we have used this method with good results that had implications for developing the service further.

\section{ACKNOWLEDGEMENTS}

We would like to thank Anna Holm, Julia Holmström, Karl Hörnell, Maria Lindqvist, Christopher Palm and Sofie Skarpsvärd for their work with the case study. We also thank the anonymous reviewers for helpful comments.

We would like to thank the reviewers for helpful comments and the editors for good service.

\section{FUNDING}

This research was partly funded by the Swedish Governmental Agency for Innovation Systems, project Food on Demand (2010-02683).

\section{REFERENCES}

Ajzen, I. (1991) The theory of planned behavior. Organization. Behav. Hum. Decision Process., 50, 179-211.

Ajzen, I. and Fishbein, M. (1977) Attitude-behavior relations: a theoretical analysis and review of empirical research. Psychol. Bull., 84, 888-918.

Andre, T.S., Hartson, H.R. and Williges, R.C. (2003) Determining the effectiveness of the usability problem inspector: a theory-based model and tool for finding usability problems. Hum. Fact., 45, 455-482.

Armitage, C.J. and Conner, M. (2001) Efficacy of the theory of planned behaviour: a meta-analytic review. Brit. J. Soc. Psychol., 40, 471-499.

Arvola, M. (2010) Interaction Design Qualities: Theory and Practice. Proc. 6th Nordic Conf. Human-Computer Interaction (NordiCHI 2010). ACM, Reykjavik, Iceland.

Bargas-Avila, J.A. and Hornbæk, K. (2011) Old Wine in New Bottles or Novel Challenges? A Critical Analysis of Empirical Studies of User Experience. CHI, pp. 1-10. ACM, Vancouver, BC, Canada.

Benbasat, I. and Barki, H. (2007) Quo vadis, TAM? J. Assoc. Inform. Syst., 8, 211-218.

Blomkvist, J., Åberg, J. and Holmlid, S. (2012) Service Walkthroughs to Support Service Development. Service Design and Service Innnovation Conference, ServDes. Espoo, Finland.

Bradley, M.M. and Lang, P.J. (1994) Measuring emotion: the selfassessment manikin and the semantic differential. J. Behav. Therapy Exp. Psychiatr., 25, 49-59.

Buchenau, M. and Fulton Suri, J. (2000) Experience Prototyping. Proc. 3rd Conf. Designing Interactive Systems: Processes, Practices, Methods, and Techniques, pp. 424-433. ACM, New York.

Chikhaoui, B. and Pigot, H. (2010) Towards analytical evaluation of human machine interfaces developed in the context of smart homes. Interact. Comput., 22, 449-464.

Clemmensen, T., Hertzum, M., Hornbæk, K., Shi, Q. and Yammiyavar, P. (2009) Cultural cognition in usability evaluation. Interact. Comput., 21, 212-220.

Conner, M., Bell, R. and Norman, P. (2002) The theory of planned behavior and healthy eating. Health Psychol., 21, 194-201.

Coughlan, P., Fulton Suri, J. and Canales, K. (2007) Prototypes as (design) tools for behavioral and organizational change: a designbased approach to help organizations change work behaviors. J. Appl. Behav. Sci., 43, 122-134.

Davis, F.D., Bagozzi, R.P. and Warshaw, P.R. (1989) User acceptance of computer technology: a comparison of two theoretical models. Manage. Sci., 35, 982-1003.

DeLone, W.H. and McLean, E.R. (2003) The DeLone and McLean model of information systems success: a ten-year update. J. Manage. Inform. Syst., 19, 9-30.

Dyrssen, C. (2010) Navigating in Heterogeneity: Architectural thinking as research. In M. Biggs and H. Karlsson (eds.), The Routledge Companion to Research in the Arts, pp. 223-239. Routledge, London, UK. 
Edvardsson, B., Gustavsson, A., Johnson, M.D. and Sandén, B. (2000) New Service Development and Innovation in the New Economy. Studentlitteratur, Lund, Sweden.

Elo, S. and Kyngäs, H. (2008) The qualitative content analysis process. J. Adv. Nurs., 62, 107-115.

Fishbein, M. and Ajzen, I. (2010) Predicting and Changing Behavior: The Reasoned Action Approach. Psychology Press, New York, USA.

Floyd, C. (1984) A systematic look at prototyping. Approaches to Prototyping, 1-18.

Forlizzi, J. and Battarbee, K. (2004) Understanding Experience in Interactive Systems. Paper 46: Human-Computer Interaction Institute.

Hartson, H.R., Andre, T.S. and Williges, R.C. (2003) Criteria for evaluating usability evaluation methods. Int. J. Human-Comput. Interact., 15, 145-181.

Hassenzahl, M. (2001) The effect of perceived hedonic quality on product appealingness. Int. J. Human-Computer Interact., 13, 481-499.

Hassenzahl, M. (2003) The Thing and I: Understanding the Relationship Between User and Product. In M. Blythe, C. Overbeeke, A.F. Monk and P.C. Wright (eds.), Funology: From Usability to Enjoyment, pp. 31-42. Kluwer, Dordrecht.

Hassenzahl, M. and Roto, V. (2007) Being and doing: a perspective on user experience and its measurement. Interfaces Mag., 72, 10-12.

Hassenzahl, M. and Tractinsky, N. (2006) User experience: a research agenda. Behav. Inform. Technol., 25, 91-97.

Henderson, R., Rickwood, D. and Roberts, P. (1998) The beta test of an electronic supermarket. Interact. Comput., 10, 385-399.

Holmlid, S. and Evenson, S. (2007) Prototyping and Enacting Services: Lessons Learned from Human-centered Methods. Proc. from the 10th Quality in Services conference, QUIS 10, Orlando, Florida.

Hvannberg, E.T., Law, E.L.-C. and Lárusdóttir, M.K. (2007) Heuristic evaluation: comparing ways of finding and reporting usability problems. Interact. Comput., 19, 225-240.

Inbar, O. and Tractinsky, N. (2011) Lowering the line of visibility: incidental users in service encounters. Behav. Inform. Technol., 31, $245-260$

Jiang, J.J., Klein, G. and Carr, C.L. (2002) Measuring information system service quality: SERVQUAL from the other side. MIS Quart., 26, 145-166.

Karahanna, E., Straub, D.W. and Chervany, N.L. (1999) Information technology adoption across time: a cross-sectional comparison of pre-adoption and post-adoption beliefs. MIS Quart., 23, 183-213.

Kettinger, W.J. and Lee, C.C. (1995) Perceived service quality and user satisfaction with the informatin services function. Decision Sci., 25, 737-765.

Kondracki, N.L., Wellman, N.S. and Amundson, D.R. (2002) Content analysis: review of methods and their applications in nutrition education. J. Nutr. Educ. Behav., 34, 224-230.

Kvale, S. and Brinkmann, S. (2009) Den kvalitativa forskningsintervjun [The Qualitative Research Interview]. Studentlitteratur AB, Lund.
Ladhari, R. (2009) A review of twenty years of SERVQUAL research. Int. J. Qual. Serv. Sci., 1, 172-198.

Langdon, P., Persad, U. and Clarkson, P.J. (2010) Developing a model of cognitive interaction for analytical inclusive design evaluation. Interact. Comput., 22, 510-529.

Lewis, C., Polson, P., Wharton, C. and Reiman, J. (1990) Testing a Walkthrough Methodology for Theory-Based Design of WalkUp-and-Use-Interfaces. Proceedings of the Computer-Human Interaction Conference, pp. 235-242. ACM Press, Seattle, WA, USA.

Li, E.Y. (1997) Perceived importance of information system success factors: a meta analysis of group differences. Inform. Manage., 32, $15-28$.

Löwgren, J. and Stolterman, E. (2004) Design av informationsteknik: materialet utan egenskaper (2:a upplagan ed.). Studentlitteratur, Lund, Sverige.

Mahatody, T., Sagar, M. and Kolski, C. (2010) State of the art on the cognitive walkthrough method, its variants and evolutions. Int. J. Human-Comput. Interact., 26, 781-785.

Mathieson, K. (1991) Predicting user intentions: comparing the technology acceptance model with the theory of planned behavior. Inform. Syst. Res., 2, 173-191.

McCurdy, M., Connors, C., Pyrzak, G., Kanefsky, B. and Vera, A. (2006) Breaking the Fidelity Barrier: An Examination of our Current Characterization of Prototypes and an Examples of a Mixed-Fidelity Success. CHI 2006 Proceedings, pp. 1233-1242. ACM, Montréal, Canada.

Nielsen, J. (1992) Finding Usability Problems through Heuristic Evaluation. Proc. ACM CHI'92 Conf., pp. 373-380. ACM, Monterey, CA.

Nørgaard, M. and Hornbæk, K. (2006) What Do Usability Evaluators Do in Practice? An Explorative Study of Think-Aloud Testing. Proc. 6th Conf. Designing Interactive Systems, pp. 209-218. ACM, University Park, PA, USA.

Norros, L., Liinasuo, M. and Hutton, R. (2011) Evaluating the potential of new technological tools for safety critical work. Interact. Comput., 23, 299-307.

Ostrom, A.L., Bitner, M.J., Brown, S.W., Burkhard, K.A., Goul, M., Smith-Daniels, V., Demirkan, H. and Rabinovich, E. (2010) Moving forward and making a difference: research priorities for the science of service. J. Serv. Res., 13, 4-36.

Parasuraman, A., Zeithaml, V.A. and Berry, L.L. (1988) SERVQUAL: a multiple-item scale for measuring consumer perceptions of service quality. J. Retail., 64, 12-40.

Paterson, B., Winschiers-Theophilus, H., Dunne, T.T., Schinzel, B. and Underhill, L.G. (2011) Interpretation of a cross-cultural usability evaluation: a case study based on a hypermedia system for rare species management in Namibia. Interact. Comput., 23, 239-246.

Pavlou, P.A. and Fygenson, M. (2006) Understanding and predicting electronic commerce adoption: an extension of the theory of planned behavior. MIS Quart., 30, 115-143.

Perugini, M. and Bagozzi, R.P. (2001) The role of desires and anticipated emotions in goal-directed behaviours: broadening and 
deepening the theory of planned behaviour. Brit. J. Social Psychol., 40, 79-98.

Pitt, L.F., Watson, R.T. and Kavan, C.B. (1995) Service quality: a measure of information systems effectiveness. MIS Quart., 19, 173-187.

Rudd, J., Stern, K. and Isensee, S. (1996) Low vs. high-fidelity prototyping debate. Interactions, 77-85.

Seth, N., Deshmukh, S.G. and Vrat, P. (2005) Service quality models: a review. Int. J. Qual. Reliab. Manage., 22, 913-949.

Sheppard, B.H., Hartwick, J. and Warshaw, P.R. (1988) The theory of reasoned action: a meta-analysis of past research with recommendations for modifications and future research. J. Consumer Res., 15, 325-343.

Sutcliffe, A., Ryan, M., Doubleday, A. and Springett, M. (2000) Model mismatch analysis: towards a deeper explanation of users' usability problems. Behav. Inform. Technol., 19, 43-55.

van Dijk, G., Minocha, S. and Liang, A. (2007) Consumers, channels and communication: online and offline communication in service consumption. Interact. Comput., 19, 7-19.

Vandermerwe, S. (2000) How increasing value to customers improves business results. Sloan Manage. Rev., 42, 27-37.
Vandermerwe, S. and Rada, J. (1988) Servitization of business: adding value by adding services. Eur. Manage. J., 6, 314-324.

Vargo, S. and Lusch, R. (2004) Evolving to a new dominant logic for marketing. J. Market., 68, 1-17.

Vargo, S. and Lusch, R. (2008) Service-dominant logic: continuing the evolution. J. Acad. Market. Sci., 36, 1-10.

Venkantesh, V., Morris, M.G., Davis, G.B. and Davis, F.D. (2003) User acceptance of information technology: toward a unified view. MIS Quart., 27, 425-478.

Watson, R.T., Pitt, L.F. and Kavan, C.B. (1998) Measuring information systems service quality: lessons from two longitudinal case studies. MIS Quart., 22, 62-79.

Wild, P.J. (2010) Longing for service: bringing the UCL conception towards services research. Interact. Comput., 22, $28-42$.

Wilkin, C. and Hewitt, B. (1999) Quality in a Respecification of DeLone and McLean's IS Success Model. In M. Khozrowpour (ed.), Proc. IRMA Int. Conf., pp. 663-372. Idea Group Publishing, Hershley, PA. 